\title{
The effects of different velogenic NDV infections on the chicken bursa of Fabricius
}

\author{
Y. W. Kristeen-Teo ${ }^{1}$, S. K. Yeap ${ }^{1}$, S. W. Tan ${ }^{1}$, A. R. Omar ${ }^{1}$, A. Ideris ${ }^{2}$, S. G. Tan ${ }^{3}$ and N. B. Alitheen ${ }^{1,3^{*}}$
}

\begin{abstract}
Background: Virulent Newcastle disease virus (NDV) was reported to cause rapid depletion of chicken bursa of Fabricius. Severe pathological condition of the organ is commonly associated with high levels of virus replication, intense inflammatory response and also the degree of apoptosis. In this study, the responses of chicken bursa of Fabricius infected with two different strains of velogenic NDV, namely AF2240 and IBS002, were investigated by observing cell population changes, oxidative stress, viral replication and cytokine expression in the organ. Subsequently, apoptosis of enriched bursal IgM+ cells was determined to help us elucidate possible host pathogen relationships between the chicken bursa of Fabricius and NDV infection.

Results: The depletion of IgM+ cells and infiltration of macrophages were observed to be higher in bursa infected with AF2240 as compared to IBS002. In line with the increment of the macrophage population, higher nitric oxide (NO) and malondialdehyde (MDA) contents which indicated higher oxidative stress were also detected in bursa infected with NDV AF2240. In addition, higher pro-inflammatory cytokines and chemokine gene expression such as chicken CXCLi2, IL-18 and IFN- $\gamma$ were observed in AF2240 infected bursa. Depletion of IgM+ cells was further confirmed with increased cell death and apoptosis of the cells in AF2240 infected bursa as compared to IBS002. However, it was found that the viral load for NDV strain IBS002 was comparatively higher than AF2240 although the magnitude of the pro- inflammatory cytokines expression and cell apoptosis was lower than AF2240.

Conclusion: The results of our study demonstrated that infection of NDV strains AF2240 and IBS002 caused apoptosis in bursa IgM+ cells and its severity was associated with increased expression of pro-inflammatory cytokines/chemokine, macrophage infiltration and oxidative stress as the infection duration was prolonged. However, of the two viruses, we observed that NDV AF2240 induced a greater magnitude of apoptosis in chicken bursa IgM+ cells in comparison to IBS002. This might be due to the high level of oxidative stress and inflammatory cytokines/chemokine as well as lower IL10 expression which subsequently led to a high rate of apoptosis in the chicken bursa of Fabricius although the detected viral load of AF2240 was lower than IBS002.
\end{abstract}

Keywords: Newcastle disease virus, B lymphocytes, Apoptosis, Oxidative stress

\section{Background}

Newcastle disease virus is classified under the order Mononegavirales in the family Paramyxoviridae, which is divided into two subfamilies, Paramyxovirinae and Pneumovirinae [1]. It was reported that a few of the first outbreaks of Newcastle disease occurred in Newcastle Upon Tyne, England and also Java, Indonesia during the

\footnotetext{
* Correspondence: noorjahan@upm.edu.my

${ }^{1}$ Institute of Bioscience, Universiti Putra Malaysia, 43400 Serdang, Selangor, Malaysia

${ }^{3}$ Faculty of Biotechnology and Biomolecular Sciences, Universiti Putra

Malaysia, 43400 Serdang, Selangor, Malaysia

Full list of author information is available at the end of the article
}

early 1900s [2]. The outbreak in Southeast Asia during 1926 spread to most of the other regions of the world and this outbreak was thought to be caused by three different genotypes of NDV which were types II, III and IV [3]. However, a similar pattern of outbreaks was also observed earlier in some areas of Central Europe [4]. In the late 1970s, NDV genotypes V and VI caused a panzootic outbreak in the Middle East [5]. In the early 2000s, NDV outbreaks in Asia were recorded in Taiwan and China caused by NDV genotype VII [6]. This virus was shown to survive when airborne in small particles, either in the laboratory or open air [7]. When infected, birds may show variable symptoms such as loss of appetite, weight loss, weakness, 
diarrhea and nervous signs [2, 8]. Post mortem examination showed severe hemorrhagic lesions of the intestine and proventriculus [9]. The pathological manifestations observed upon NDV infections are contributed by factors such as the strain of the virus, species of birds, concurrent diseases and preexisting immunity which can affect the severity of the disease [10].

Avian bursa of Fabricius had been identified to play an important role in the development of B lymphocytes as studies showed that the surgical removal of this organ during the embryonic stage of a bird compromised its antibody production thus leading to immunosuppresion $[11,12]$. The organ serves as an essential site for generation of antibody diversity by gene conversion. It was reported to serve as a primary lymphoid organ until the age of five to 6 weeks and after that as a peripheral lymphoid organ [13]. Primarily this organ consisted of 98\% B lymphocytes [14] but infiltration of other cells, such as $\mathrm{T}$ cells and macrophages was observed in response to viral infection [15]. The bursa of Fabricius was involved in host responses against poultry virus not only by Infectious bursal disease virus (IBDV) [16-18], in which the virus infection caused cell population and cytokine expression changes but also upon NDV infection. Several reports showed that virulent NDV strains cause rapid depletion of the bursa of Fabricius [19-21] and the severe pathology in immune organs caused by virulent NDV strains is associated with high levels of virus replication and an intense inflammatory response $[22,23]$. Also, apoptosis was reported to play a role in the pathogenesis of NDV as well. It was demonstrated that the amount of apoptosis was proportional to the severity of the clinical disease elicited by the strains [20, 24]. In this study, we investigated the response of chicken bursa of Fabricius upon infection with two different strains of Malaysian isolates of velogenic NDV. Oxidative stress caused by the virus infection was also evaluated by detecting the nitric oxide content in the organ. Apoptosis studies on B lymphocytes, which are the largest cell population in the organ, was done and correlated with viral load detection in the organ to help us elucidate possible host pathogen relationships between the chicken bursa of Fabricius and Newcastle disease virus.

\section{Methods}

\section{Experimental design}

The study was approved by the Institutional Animal Care and Use Committee (IACUC), Universiti Putra Malaysia (UPM). SPF layer chicken eggs $(n=80)$ were obtained from the Veterinary Research Institute (Ipoh, Malaysia), hatched in the Laboratory of Vaccines and Immunotherapeutics, Institute of Biosciences, UPM and raised until the age of 35 days old. The trial was conducted in UPM Faculty of Veterinary Medicine experimental animal facility where the different groups of birds were kept separately in different rooms and cages. The birds were then randomly divided into three groups with the first two groups $(n=30)$ being infected with $10^{6}$ ELD50 of NDV strain AF2240 and IBS002, respectively. The viruses were delivered to the chickens via ocular $(50 \mu \mathrm{l})$ and nasal $(50 \mu \mathrm{l})$ routes using $1 \mathrm{ml}$ syringe. The remaining birds were treated with PBS and served as the control group. Ten birds from each infected group were then observed, sacrificed and necropsized at days 1, 3 and 4 post infection whereas the control chickens were sacrificed at day 4 . Chicken bursa of Fabricius was removed and cut into two parts, which one for oxidative stress study and RNA extraction for gene expression purposes. Meanwhile the other part of the organ was used for enrichment of IgM+ cells, which were subsequently subjected to apoptosis related assays such as acridine orange/propidium iodide (AO/PI) double staining, Annexin $\mathrm{V}$ apoptosis and DNA cell cycle assays. Prior to cell isolation, a cell count was performed using a hemacytometer and a portion of the cells $\left(2 \times 10^{6}\right.$ cells) was subjected to flow cytometry analysis to for cell population study.

\section{Virus isolates}

The viruses used in this study are velogenic isolates Chicken/Malaysia/Perak/AF2240/1960 (AF2240) and Commercial broiler chicken/Malaysia/Johor/IBS002/ 2011 (IBS002). NDV AF2240 is a viscerotropic velogenic, genotype VIII strain that is used as a vaccine challenge virus in Malaysia [25]. The intracerebral pathogenicity index (ICPI) for AF2240 was 1.9 [26] while its mean death-time (MDT) was $48 \mathrm{~h}$ [27]. On the other hand, NDV isolate IBS002 was characterized as a virulent genotype VII strain based on the multiple basic amino acid motif of the fusion (F) cleavage site 112RRRKGF117 and length of the C-terminus extension of the hemagglutinin-neuraminidase $(\mathrm{HN})$ gene with the ICPI and MDT at 1.76 and $51.2 \mathrm{~h}$ respectively [28]. Both viruses are belonged to and owned by Institute of Bioscience, Universiti Putra Malaysia.

\section{Immunophenotyping of SPF chicken bursa of Fabricius}

To study the cell population changes in chicken bursa when infected with NDV AF2240 and IBS002, immunophenotyping using flowcytometry was conducted. Single cells were isolated from chicken bursa of Fabricius at days 1, 3 and 4 post infection. In brief, the organs were removed $(n=5)$, washed with PBS and cut into pieces using a scalpel, before being meshed through $70 \mu \mathrm{m}$ sterile wire mesh screen (SPL Life Sciences, China). The single cells were then collected and washed twice in PBS-BSA-EDTA. After that, the pellet was subjected to 
Histopaque 1119 (Sigma, USA) at $400 \mathrm{~g}$ for $40 \mathrm{~min}$. The lymphocyte layers were collected and washed twice again with PBS-BSA-EDTA. A cell count was performed using a hemacytometer and a number of $1 \times 10^{6}$ cells/ tube were incubated with $10 \mu \mathrm{g} / 10 \mu \mathrm{L}$ mouse antichicken CD3-FitC, clone CT-3 and mouse anti-chicken CD4-PE, clone CT-4 (tube 1), mouse anti-chicken CD3FitC, clone CT-3 and mouse anti-chicken CD $8 \alpha-P e r C p$, clone CT8 (tube 2), mouse anti-chicken IgM-PE, clone M-1 (tube 3) and mouse anti-chicken monocyte/macrophage-PE, clone KUL01 (tube 4) antibodies (Southern Biotech, USA) for $45 \mathrm{~min}$ in the dark. The cells were then washed again with PBS and lastly resuspended in $1 \mathrm{ml}$ PBS. Flow cytometer analysis was carried out using a FACSCalibur machine with CellQuest Pro software (BD Bioscience, USA). A total of 20,000 events were analyzed via gating the chicken lymphocytes using forward and side scatter before the data for positive staining of different fluorescence were collected. The average cell numbers of CD4, CD8, IgM and macrophages are listed in Table 1.

\section{Oxidative stress (NO and MDA detection)}

Upon NDV AF2240 and IBS002 infection, oxidative stress in chicken bursa of Fabricius was observed and compared by measuring nitric oxide (NO) and malondialdehyde (MDA) level. Chicken bursas of Fabricius at different time point after being infected with NDV AF2240 and IBS002 were cut and meshed before the organ homogenate was subjected to NO and MDA detection ( $n=5$ from each group). For NO evaluation, $150 \mu \mathrm{L}$ of the sample homogenate was added with $20 \mu \mathrm{L}$ of Griess Reagent (Invitrogen, USA) and $130 \mu \mathrm{L}$ of deionized water in a microplate. The mixture was incubated for $30 \mathrm{~min}$ at room temperature. After the incubation, the sample absorbance was measured at $548 \mathrm{~nm}$ using $\mu$ Quant ELISA Reader (Bio-Tek Instruments, USA). Meanwhile,
MDA activity was determined by measuring the thiobarbituric acid-reactive substance (TBARS). In brief, $100 \mu \mathrm{L}$ of bursa homogenate was added with $12.5 \mu \mathrm{L}$ butyhydroxytoulene $(8.8 \mathrm{mg} / \mathrm{mL}), 250 \mu \mathrm{L} \mathrm{30 \%} \mathrm{trichloroacetic} \mathrm{acid} \mathrm{and}$ $400 \mu \mathrm{L}$ of PBS before the mixture was mixed and incubated on ice for $2 \mathrm{~h}$. Subsequently, the mixture was spun at $300 \mathrm{~g}$ for $15 \mathrm{~min}$ and the supernatant was collected and added with $37.5 \mu \mathrm{L}$ of $0.1 \mathrm{M}$ EDTA and $125 \mu \mathrm{L} 1 \%$ thiobarbituric acid before being subjected to boiling for $15 \mathrm{~min}$. The mixture would then turn pink and the absorbance was read at 532 and $600 \mathrm{~nm}$ using a $\mu$ Quant ELISA Reader (Bio-Tek Instruments, USA). The absorbance measured was then compared with the standard made with malonaldehyde tetramethylacetal solutions at different concentrations and the MDA activity was expressed as nmol $\mathrm{MDA} / \mathrm{g}$ protein.

\section{Detection of viral load and cytokine expression by real time PCR}

TaqMan probe based real time PCR was used to determine viral load in chicken samples infected with NDV AF2240 and IBS002. RNA was isolated from both crude cells and enriched IgM+ cells. Bursas of Fabricius from the control and infected chickens were removed $(n=5$ from each group) and RNA from each sample was extracted using TRIZOL (Invitrogen, USA) following the instruction recommended by the manufacturer. The concentration and purity of the extracted RNA were measured by using a spectrophotometer (DU ${ }^{\circ} 730$, Beckman Coulter, USA) at the wavelength of $260 \mathrm{~nm}$ over $280 \mathrm{~nm}$ before being subjected to cDNA synthesis using iScriptcDNA Kit (Biorad, USA) incubated in a thermal cycler for $5 \mathrm{~min}$ at $25^{\circ} \mathrm{C}, 30 \mathrm{~min}$ at $42{ }^{\circ} \mathrm{C}$ and $5 \mathrm{~min}$ at $85^{\circ} \mathrm{C}$. The cDNA was then subjected to NDV viral load detection using usingiQSupermix (Biorad, USA) together with forward primer $5^{\prime}$ TCCGCAAGATCCAAGGGTCT-3', reverse primer 5'CGCTGTTGCAACCCCAAG-3' and Taqman probe 5'-

Table 1 Average cell number of different lymphocytes subsets after infected with NDV AF2240 and NDV IBS002

\begin{tabular}{|c|c|c|c|c|c|}
\hline \multirow[t]{2}{*}{ Groups } & & \multicolumn{4}{|c|}{ Average cell numbers } \\
\hline & & Control & Day 1 & Day 3 & Day 4 \\
\hline \multirow[t]{2}{*}{ CD4 } & NDV AF2240 & $0.79 \times 10^{5} \pm 50$ & $0.34 \times 10^{5} \pm 12^{*}$ & $0.46 \times 10^{5} \pm 21^{* *}$ & $1.46 \times 10^{5} \pm 52^{* * * a}$ \\
\hline & NDV IBS002 & $0.79 \times 10^{5} \pm 50$ & $0.33 \times 10^{5} \pm 22^{*}$ & $0.46 \times 10^{5} \pm 12^{* *}$ & $1.08 \times 10^{5} \pm 20^{* * * b}$ \\
\hline \multirow[t]{2}{*}{ CD8 } & NDV AF2240 & $0.27 \times 10^{5} \pm 12$ & $0.71 \times 10^{5} \pm 22^{* a}$ & $1.10 \times 10^{5} \pm 115^{* * a}$ & $1.40 \times 10^{5} \pm 21^{* * *_{a}}$ \\
\hline & NDV IBS002 & $0.27 \times 10^{5} \pm 12$ & $0.23 \times 10^{5} \pm 10^{* b}$ & $0.65 \times 10^{5} \pm 13^{* * b}$ & $1.58 \times 10^{5} \pm 11^{* * * b}$ \\
\hline \multirow[t]{2}{*}{$\lg M$} & NDV AF2240 & $1.78 \times 10^{6} \pm 36$ & $1.76 \times 10^{6} \pm 83$ & $1.43 \times 10^{6} \pm 29^{* a}$ & $1.24 \times 10^{6} \pm 101^{* *_{a}}$ \\
\hline & NDV IBS002 & $1.78 \times 10^{6} \pm 36$ & $1.73 \times 10^{6} \pm 53$ & $1.64 \times 10^{6} \pm 24^{* b}$ & $1.37 \times 10^{6} \pm 115^{* * b}$ \\
\hline \multirow[t]{2}{*}{ Macrophage } & NDV AF2240 & $0.69 \times 10^{5} \pm 21$ & $0.35 \times 10^{5} \pm 24^{*}$ & $0.95 \times 10^{5} \pm 47^{* * a}$ & $2.86 \times 10^{5} \pm 16^{* * * a}$ \\
\hline & NDV IBS002 & $0.69 \times 10^{5} \pm 21$ & $0.40 \times 10^{5} \pm 66^{*}$ & $1.08 \times 10^{5} \pm 63^{* * b}$ & $1.70 \times 10^{5} \pm 15^{* * * b}$ \\
\hline
\end{tabular}

Data representing average cell number of $\mathrm{CD} 4+, \mathrm{CD} 8+$, IgM and macrophages with standard deviation from chicken bursa of Fabricius cells of five chickens from each group.

Different asterisk signs show significant difference between infection time points $(P \leq 0.05)$

Different alphabets show significant difference between different strains of NDV $(P \leq 0.05)$. 
(FAM)-AAGCGTTTCTGTCTCCTTCCTCCA-(BHQ)-3' . The cycling program consists of $95{ }^{\circ} \mathrm{C}$ for $5 \mathrm{~min}$ and followed by 39 cycles of $95{ }^{\circ} \mathrm{C}$ for $10 \mathrm{~s}, 56{ }^{\circ} \mathrm{C}$ for $30 \mathrm{~s}$ and $72{ }^{\circ} \mathrm{C}$ for $20 \mathrm{~s}$. Standard curves for detection of NDV AF2240 and IBS002 was provided in Additional file 1: Figure S1. As for cytokines expression, following primers and probes were used: forward primer 5'-GTGAAGAAGGTGAAAGATATCAT GGA-3', reverse primer 5'- GCTTTGCGCTGGAT TCTCA- $3^{\prime}$ and probe $5^{\prime}$-(FAM)-TGGCCAAGCTCCC GATGAACGA-(BHQ1)-3' for IFN- $y$ expression; forward primer $5^{\prime}$-GCCCTCCTCCTGGTTTCAG-3', reverse primer $5^{\prime}$-TGGCACCGCAGCTCATT $-3^{\prime}$ and probe $5^{\prime}$-(FAM)-TCTTTACCAGCGTCCTACCTTGC GACA-(BHQ1)-3' for CXCLi2 expression; forward primer 5'-AGGTGAAATCTGGCAGTGGAAT-3', reverse primer $5^{\prime}$-ACCTGGACGCTGAATGCAA-3' and probe 5' -(FAM)-CCGCGCCTTCAGCAGGGATG-(BHQ1)-3' for IL18 expression; forward primer $5^{\prime}$-CATGCTGCTGGG CCTGAA-3', reverse primer 5'-CGTCTCCTTGATCT GCTTGATG-3' and probe $5^{\prime}$-(FAM)-CGACGATTCGGC GCTGTCACC-(BHQ1)-3' for IL10 expression; as well as forward primer 5'-GAACGGGAAACTTGTGAT-3', reverse primer $5^{\prime}$-GACTCCACAACATACTCA-3' and probe 5' -(FAM)-CGCCATCACTATCTTCCAGG-(BHQ1)-3' for GAPDH expression as reference gene. The real time PCR cycling program was set up as 1 cycle of $95{ }^{\circ} \mathrm{C}$ for $5 \mathrm{~min}$, followed by 40 cycles of $95^{\circ} \mathrm{C}$ for $20 \mathrm{~s}, 58^{\circ} \mathrm{C}$ for $20 \mathrm{~s}$ (IFNy, CXCLi2, IL18 and IL10) or $60{ }^{\circ} \mathrm{C}$ for $30 \mathrm{~s}$ (GAPDH), depending on primer annealing temperature. Viral load was calculated by using standard curve (Additional file 1: Figure S1) with the following formula:

$$
\text { Log Quantity }=\frac{C t-b}{m}
$$

$\mathrm{Ct}=$ cycle threshold value.

$\mathrm{b}=\mathrm{y}$-intercept.

$\mathrm{m}=$ slope.

Relative fold change for CXCLi2, IFN- $y$ and IL18 was calculated using $2^{-\Delta \Delta \mathrm{Ct}}$ method. Meanwhile, IL10 was expressed as relative $\Delta \mathrm{Ct}$ gene expression normalized with GAPDH because no IL10 was detected on day 1 post infection and uninfected controls.

\section{Isolation of enriched B lymphocyte population and cell viability assessment}

At days 0, 1, 3 and 4 post infection, single cells were harvested from chicken bursa of Fabricius of SPF chickens ( $n=10$ from each group). The cells were then stained with $10 \mu \mathrm{g} / 10 \mu \mathrm{L}$ PE-labelled $\operatorname{IgM}$ for $45 \mathrm{~min}$ and washed twice with PBS. Subsequent to that, the cells were labelled with $20 \mu \mathrm{L}$ of anti-PE microbeads for $30 \mathrm{~min}$ prior to magnetic isolation of pure $\mathrm{B}\left(\operatorname{IgM}^{+}\right)$ cell population using a LS column (Miltenyi Biotec, Germany). The enriched B cells were then washed twice with PBS before proceeding to cell viability testing by using the colorimetric 3-(4,5-dimethylthiazol2-yl)-2,5-diphenyl tetrazolium bromide (MTT) assay as described previously [29].

\section{Acridine orange/propidium iodide (AO/PI) double staining assay}

The enriched IgM + B cell suspension was washed with PBS twice and $10 \mu \mathrm{L}$ of the cells were put on a glass slide. Acridine orange $(50 \mu \mathrm{g} / \mathrm{ml})$ and propidium iodide $(50 \mu \mathrm{g} / \mathrm{ml})$ were mixed together at a 1:1 ratio to a total volume of $1 \mathrm{ml}$. After that, $10 \mu \mathrm{l}$ of the mixture was added to the cells on a glass slide and resuspended carefully. The slide was then analyzed using a fluorescent microscope (Nikon, Japan) within $30 \mathrm{~min}$. This assay permitted clear differentiation of viable and nonviable cells using two different fluorescent dyes. Through counting a total population of 200 cells, the percentage of viable, apoptotic and necrotic cells were determined. Besides, cells with condensed chromatin and blebbing were also considered as apoptotic cells (Fig. 1). The experiment was repeated using three biological replicates for each group.

\section{Annexin $\mathrm{V}$ apoptosis assay}

Enriched IgM + B lymphocytes of every group were harvested and subjected to Annexin V apoptosis assay. The cells were washed with PBS and stained with Annexin V FITC (BD Biosciences, USA) for 20 min prior to analysis using a FACSCalibur machine with CellQuest Pro Software (BD Bioscience, USA). The assay was conducted in triplicates.

\section{DNA cell cycle analysis}

A total of $1 \times 10^{6}$ enriched IgM+ B cells was collected from each sample group and fixed in $80 \%$ ethanol overnight at a temperature of $-20{ }^{\circ} \mathrm{C}$. The samples were then re-pelleted and washed twice by using PBS-SodiumAzide-EDTA buffer. Finally, the pellet was dissolved in $1 \mathrm{~mL}$ of PBS buffer containing $0.1 \%$ Triton X-100, $10 \mathrm{mM}$ EDTA, $50 \mu \mathrm{g} / \mathrm{mL}$ RNase and $2 \mu \mathrm{g} / \mathrm{ml} \mathrm{SYTOX}$ green in the dark, followed by incubation for at least $30 \mathrm{~min}$ on ice. The samples were then subjected to analysis by flow cytometry using a FACSCalibur machine with CellQuest Pro software (BD Biosciences, USA).

\section{Statistical analysis}

The Graphpad Prism 6.0 software was used to aid the statistical analysis of the results. The results were expressed as mean \pm standard deviation and subjected to one way ANOVA or two-way ANOVA test, followed by the Bonferroni procedure with infection 


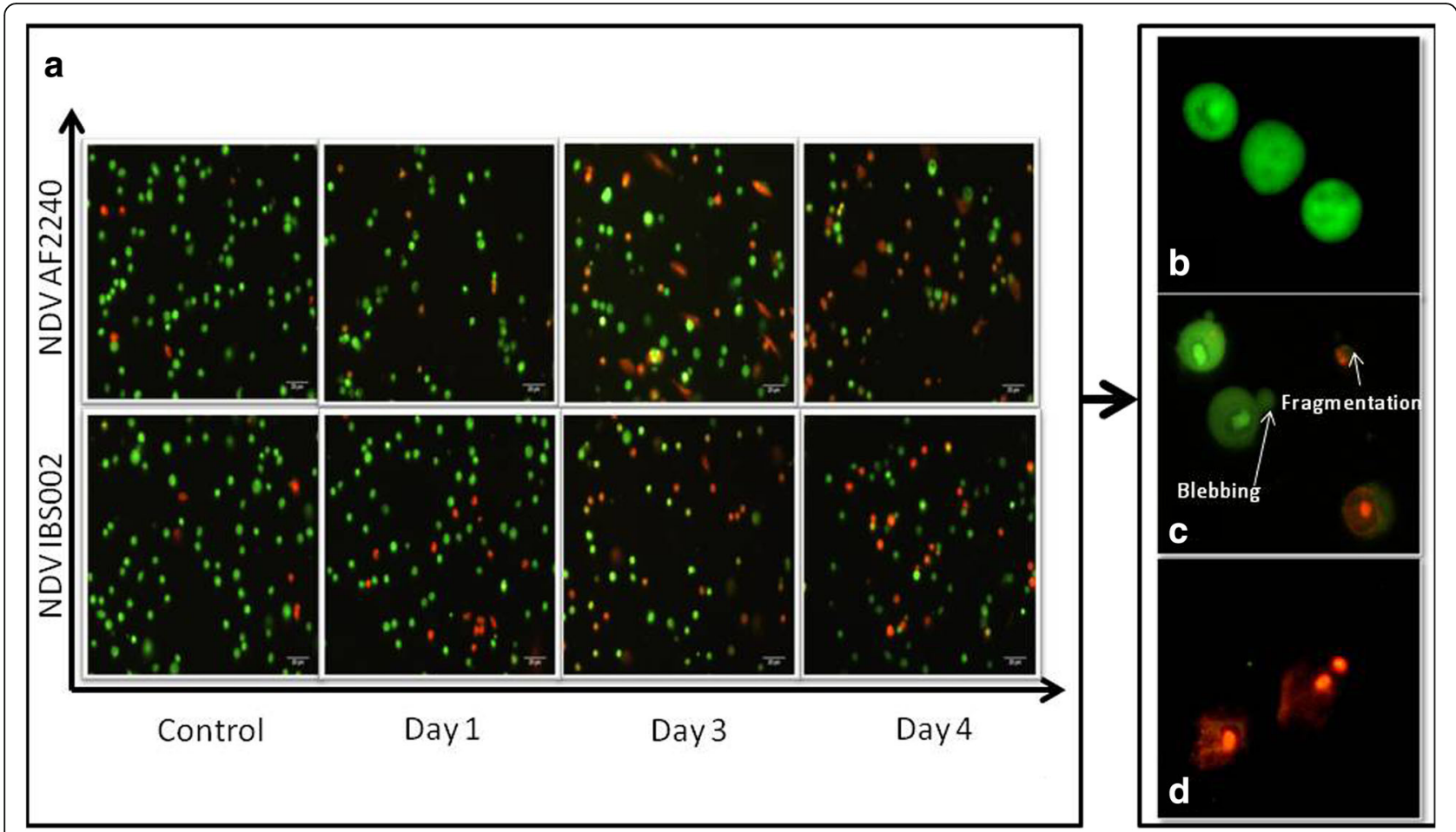

Fig. 1 AO/PI assay of chicken enriched B lymphocytes infected with (a) NDV AF2240 and NDV IBS002 at day 1, 3 and 4 post infections, magnification 400x; b Viable cells; c Early Apoptotic cells where arrow indicating membrane blebbing and chromation condensation, red cells are late apoptotic cells; d Late apoptotic or necrotic cells, magnification 400x; AO (excitation: 488 nm, emission: 545 nm), PI (excitation: 535 nm, emission: 617 nm)

time points and virus genotypes as main effects. Results with $P<0.05$ were considered as being statistically significant.

\section{Results}

\section{Immunophenotyping}

In chicken bursa, cell population changes were observed when the animals were infected with different strains of velogenic NDV. The average numbers of different lymphocyte subsets were counted and the results are shown in Table 1. Similar patterns of CD4+ cell population changes were observed upon infection by both NDV AF2240 and IBS002. The infection caused depletion of CD4+ T cells on days 1 and 3 post infection, but on the fourth day, NDV AF2240 caused the CD4+ cell number to increase to $1.46 \times 10^{5}$ from the initial $0.79 \times$ $10^{5}$ cells while NDV IBS002 increased the number to $1.08 \times 10^{5}$ cells. CD8+ cells were found to gradually increase along with the time of infection by both viruses, with higher increments during day 1 and day 3 post infection caused by NDV AF2240 infection, whereas on the fourth day of infection, higher CD8+ cell number was observed in the chicken bursa infection by NDV IBS002. B lymphocytes, which were measured by the expression of IgM, were reported to decline significantly in cell number upon infection with both genotypes of NDV starting on day three after infection. However, infection with NDV AF2240 resulted in a greater decline in IgM+ cell number from an initial figure of $1.78 \times 10^{6} \pm 36$ cells to $1.24 \times 10^{6} \pm 101$ cells (Table 1 ) compared to NDV IBS002 for which the cell number of IgM+ cells reached $1.37 \times 10^{6} \pm 115$ cells at day four post infection (Table $1)$. Also, it was observed that the macrophage population increased upon infection with both genotypes of NDV but NDV AF2240 resulted in a higher peak in macrophage cell number at $2.86 \times 10^{5} \pm 16$ cells compared to NDV IBS002 at $1.70 \times 10^{5} \pm 15$ cells on the fourth day after infection.

\section{Oxidative stress evaluation (NO and MDA detection)}

Upon infection with virus, NO is considered as a proinflammatory mediator due to its over production. The level of NO in the chicken bursa of Fabricius was measured at 1, 3 and 4 days post infection. Figure 2 shows the NO levels detected in the chickens' bursa after infection with the two viral genotypes respectively. According to Fig. 2, the level of nitric oxide content in chicken bursa of Fabricius upon NDV AF2240 infection increased from an initial of $33.06 \pm 4.2 \mu \mathrm{M}$ of nitric oxide to the highest level of $92.89 \pm 2.5 \mu \mathrm{M}$ on the fourth day of infection whereas NDV IBS002 caused increment of nitric oxide level to $81.02 \pm 6.4 \mu \mathrm{M}$ in the organ. A 


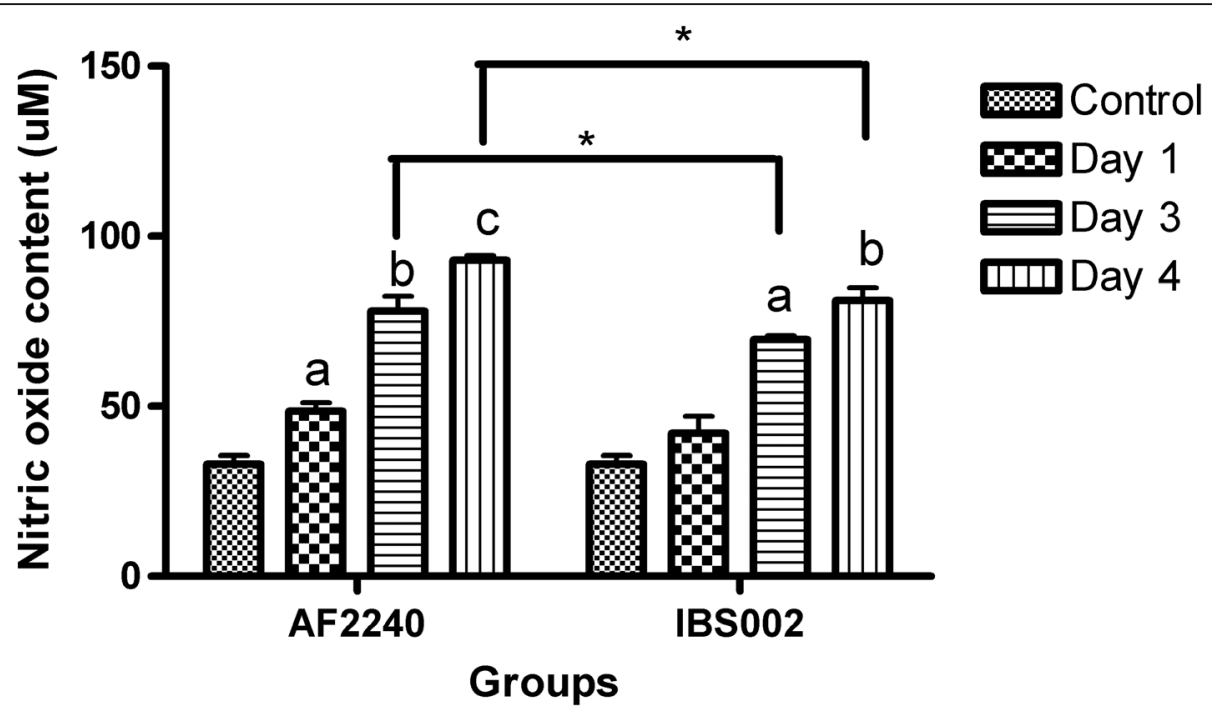

Fig. 2 The nitric oxide content in the bursa of 3-week-old chicken infected with NDV AF2240 and IBS002 at day 1,3 and 4 post infection. Significant differences were observed using two-ways ANOVA by using strains of NDV and infection time points as effectors. Asterisk signs show significant difference between different strains of NDV $(P \leq 0.05)$ while different alphabets show significant difference between different infection time points $(P \leq 0.05)$

similar trend of increment in MDA level was also observed in the chicken bursa of Fabricius after infection with the two different genotypes of NDV. Figure 3 shows that NDVAF2240 caused a significant elevation of MDA content in chicken bursa starting on day 3 post infection compared to the control group and reached its highest peak during day 4 at $28.26 \pm 1.6 \mathrm{nM}$ of MDA/g of protein. Meanwhile, IBS002 caused a significant increase of the MDA level at day 1 post infection and reached $24.84 \pm 0.5 \mathrm{nM}$ of MDA/g of protein at day 4 .

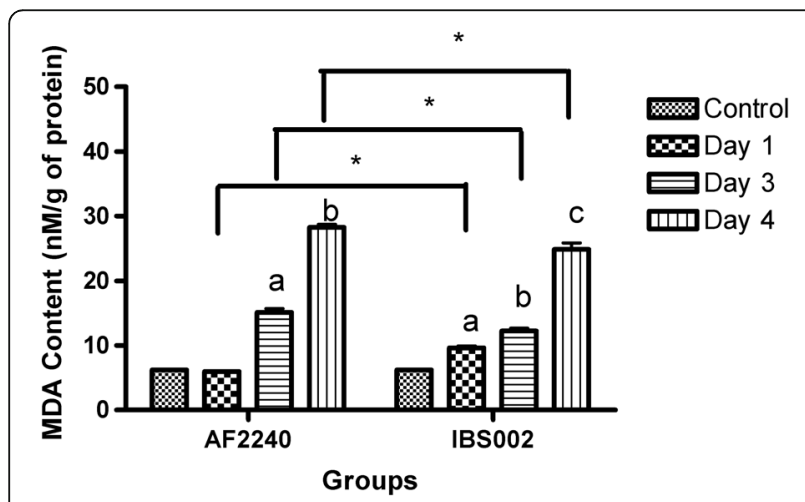

Fig. 3 The MDA content in the bursa of 3-week-old chicken infected with NDV AF2240 and IBS002 at day 1, 3 and 4 post infection. Significant differences were observed using two-ways ANOVA by using strains of NDV and infection time points as effectors. Asterisk signs show significant difference between different strains of NDV $(P \leq 0.05)$ while different alphabets show significant difference between different infection time points $(P \leq 0.05)$
Detection of viral load and cytokines by real time PCR

The results showed that both viruses RNA could be detected in the samples starting on day 3 post infection and that the viral load increased on the following day. Table 2 shows that a higher viral load was detected in both chicken bursa and IgM + cells infected by NDV IBS002 compared to AF2240. On the other hand, Fig. 4 shows the expressions of IFN- $\gamma$, CXCLi2 and IL-18 detected in chicken bursa upon infection. As is shown in Fig. 4, the infection of NDV AF2240 significantly increased expression of IFN-y starting on day 1 post infection as compared to the control group and then this was further elevated to 83 - fold change on day 3 . On day 4 post infection, expression of IFN- $\gamma$ was recorded at 22fold compared to the control group. Both IL-18 and CXCLi2 gene expressions were also up-regulated during the infection of AF2240. The IL-18 expressions were upregulated at 8-, 42- and 14 - folds at days 1, 3 and 4 post infection while the CXCLi2 expressions at 7-, 21- and 12- folds (Fig. 4). Significant changes of IFN-y, IL-18 and CXCLi2 gene expressions were observed with NDV AF2240 infection at all different time points of infection. Meanwhile, no significant changes of IFN- $\gamma$ and CXCLi2 were observed in chicken bursa upon NDV IBS002 infection. The expression of IL-18 was increased to $25-$ fold at days 1 and 3 post infection, but decreased to 11 fold on the next day. Conversely, IL-10 was detected on day 3 and day 4 post infection of NDV AF2240 and IBS002 in the bursa (Fig. 4) but none on day 1 and uninfected control. 
Table 2 TaqMan real time PCR result of detection of NDV AF2240 and IBS002 virus in the chicken bursa and IgM ${ }^{+}$cells population isolated from chicken bursa of Fabricius

\begin{tabular}{|c|c|c|c|c|c|}
\hline & \multirow[t]{2}{*}{ Samples } & \multicolumn{2}{|l|}{$\mathrm{C}(\mathrm{t})$ mean } & \multicolumn{2}{|c|}{ Viral copy number $(\log 10)$} \\
\hline & & AF2240 & IBS002 & AF2240 & IBS002 \\
\hline & Control & $N / D$ & $N / D$ & $\mathrm{~N} / \mathrm{D}$ & N/D \\
\hline \multirow[t]{3}{*}{ Bursa of Fabricius } & Day 1 & $\mathrm{~N} / \mathrm{D}$ & $N / D$ & N/D & N/D \\
\hline & Day 3 & $29.85 \pm 0.28$ & $26.24 \pm 0.88$ & $10.34^{* a}$ & $11.43^{* b}$ \\
\hline & Day 4 & $28.33 \pm 0.18$ & $23.20 \pm 0.53$ & $10.80^{* a}$ & $12.34^{* * b}$ \\
\hline \multirow[t]{4}{*}{$\lg M+$ cells } & Control & $\mathrm{N} / \mathrm{D}$ & N/D & N/D & $N / D$ \\
\hline & Day 1 & $N / D$ & $\mathrm{~N} / \mathrm{D}$ & $\mathrm{N} / \mathrm{D}$ & $\mathrm{N} / \mathrm{D}$ \\
\hline & Day 3 & $35.10 \pm 0.27$ & $28.74 \pm 0.03$ & $8.76^{* a}$ & $10.68^{* b}$ \\
\hline & Day 4 & $28.48 \pm 0.16$ & $26.82 \pm 1.3$ & $10.10^{* * a}$ & $11.25^{* * b}$ \\
\hline
\end{tabular}

N/D stands for not detectable. No amplification of NDV gene was detected throughout whole qPCR cycling program.

All results represent the mean \pm standard deviation

Different asterisk signs show significant different between infection time points $(P \leq 0.05)$

Different alphabets show significant different between different strains of NDV $(P \leq 0.05)$.

NDV AF2240, R2 $=0.984$, Slope $=3.13$

\section{Cell viability and apoptosis assay}

The cell viability of enriched B lymphocytes, which are the largest cell population in chicken bursa of Fabricius was examined upon infection with the NDV viruses (Table 3). The results showed that the infection of NDV virus caused increment of cell death events in IgM cells in chicken bursa of Fabricius as the duration of infection increased (Table 3). MTT assay was performed and the percentages of viable cells of virus infected groups were normalized with the control group. It was found that NDV AF2240 caused higher cell death in the enriched B lymphocytes compared to NDV IBS002 (Table 3). These results were further confirmed with the apoptosis assays using AO/PI and Annexin V binding assays. As is shown in Table 4, it was found that infection of the chicken bursa by NDV AF2240 caused a higher percentage of apoptotic IgM+ cells in the organ. A similar trend of results was observed in the Annexin $\mathrm{V}$ binding assay where a greater number of Annexin $\mathrm{V}$ positive IgM+ cells were detected in chicken bursa during infection with NDV AF2240 (Table 3). In agreement with these results, it was observed that the infection of NDV viruses caused increment of the sub G0/G1 population in the enriched IgM+ cells. DNA fragmentation, which is one
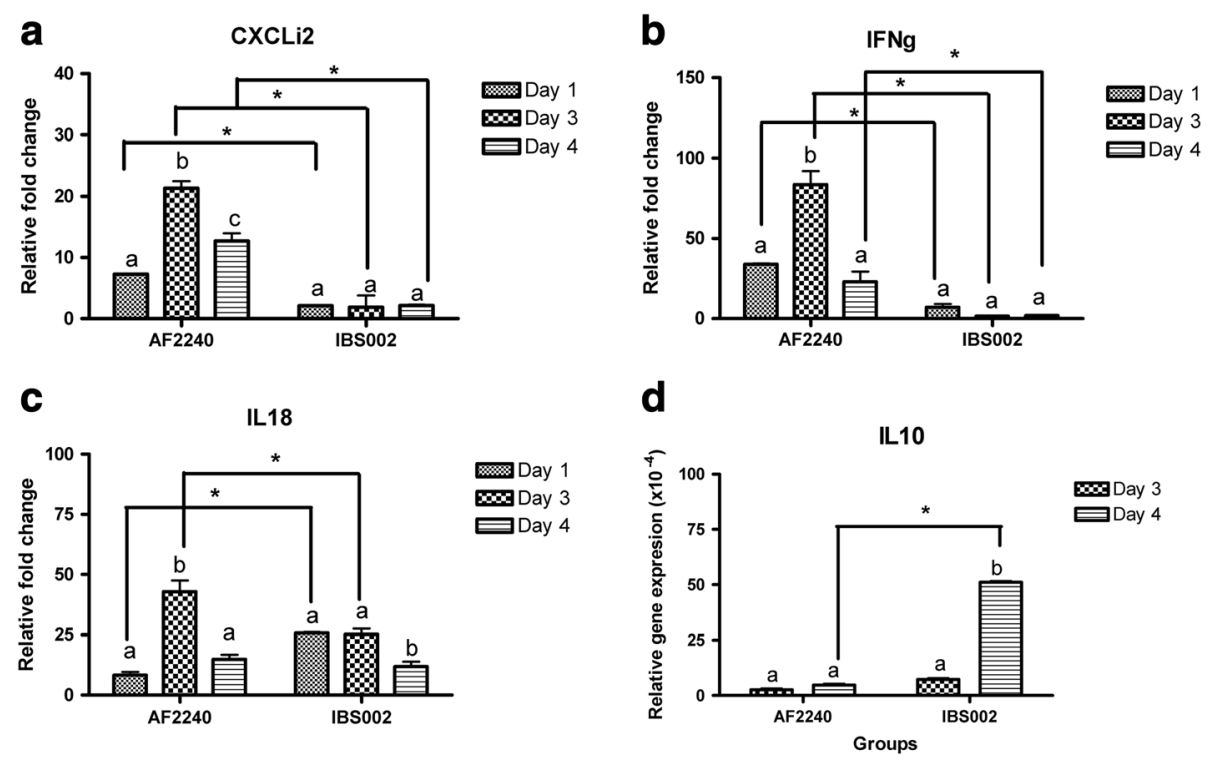

Fig. 4 The normalized fold expression of (a) CXCLi2, (b) IFN- $\gamma$ and (c) IL-18 and normalized Cq value of (d) IL10 in the bursa of 3-week-old chickens infected with NDV AF2240 or IBS002 at 1, 3 and 4 day post infection. Significant differences were observed using two-ways ANOVA by using strains of NDV and infection time points as effectors. Asterisk signs show significant difference between different strains of NDV $(P \leq 0.05)$ while different alphabets show significant difference between different infection time points $(P \leq 0.05)$ 
Table 3 MTT assay, AO/PI apoptotic population and Annexin $V$ apoptotic population of chicken bursa of Fabricius enriched $\operatorname{lgM}^{+}$B lymphocytes infected with NDV AF2240 and IBS002. The differences between the control group and infected group were determined by one-way ANOVA

\begin{tabular}{llllll}
\hline Assays & NDV strains & Control & 1 d.p.i & 3 d.p.i & 4 d.p.i \\
\hline MTT viable IgM cells (\%) & AF2240 & $100 \pm 0.32$ & $81.48 \pm 0.36^{*}$ & $60.86 \pm 0.44^{* *}$ & $42.06 \pm 0.19^{* * *_{a}}$ \\
& IBS002 & $100 \pm 0.32$ & $85.42 \pm 0.22^{*}$ & $65.78 \pm 0.12^{* *}$ & $53.15 \pm 0.24^{* * b_{b}}$ \\
AO/PI apoptotic IgM cell count (\%) & AF2240 & $2.02 \pm 0.90$ & $4.37 \pm 0.30^{*}$ & $15.34 \pm 0.80^{* *}$ & $17.81 \pm 3.70^{* *}$ \\
& IBS002 & $2.02 \pm 0.90$ & $3.29 \pm 6.70$ & $10.98 \pm 4.40^{*}$ & $14.91 \pm 3.10^{* *}$ \\
Annexin V positive IgM cell population (\%) & AF2240 & $3.29 \pm 1.44$ & $19.72 \pm 2.13^{* a}$ & $14.35 \pm 1.26^{* *}$ & $34.49 \pm 2.50^{* * * a}$ \\
& IBS002 & $3.29 \pm 1.44$ & $9.22 \pm 2.20^{* b}$ & $12.15 \pm 1.35^{*}$ & $22.81 \pm 1.14^{* * b}$ \\
\hline
\end{tabular}

All results represent the mean \pm standard deviation $(n=3)$

Different asterisk signs show significant different between infection time points $(P \leq 0.05)$.

Different alphabets show significant different between different strains of NDV $(P \leq 0.05)$.

of the apoptosis hallmarks, can be indicated by the occurrence of the sub G0/G1 population. As is shown in Fig. 5, the population of sub G0/G1 increased over the infection time of NDV AF2240 and IBS002. It was also shown that as in the previous findings, NDV AF2240 caused higher frequency of DNA fragmentation compared to IBS002.

\section{Discussion}

Immune reaction to viral invasion is important to combat virus growth and to minimize any damage that can be imposed on the host cells [30]. In this study, the host immune response in the bursa of Fabricius, an organ mainly colonized by B lymphocytes, was assessed upon infection by the avian virus NDV genotype VII IBS002 and genotype VIII AF2240.

The cell population in the chicken bursa was evaluated by flow cytometry and the results showed that in normal chickens, this organ was predominantly occupied by B lymphocytes while the $\mathrm{T}$ lymphocyte and macrophage populations were at minimal cell numbers. Different from the cell population changes in chicken spleen upon NDV infection where CD4+ and CD8+ cells declined in their cell numbers when invaded by the two different NDV genotypes [31], our results showed infiltration of both CD4+ and CD8+ T lymphocytes in NDV AF2240

Table 4 Summary of results

\begin{tabular}{|c|c|c|}
\hline & Infection of NDV AF2240 & Infection of NDV IBSO02 \\
\hline Cell population changes & $\begin{array}{l}\text { - Increment of T lymphocytes and macrophages, } \\
\text { depletion of B lymphocytes compared to } \\
\text { uninfected control. } \\
\text { - Higher increment of macrophages and depletion } \\
\text { of B lymphocytes compared of IBS002 infection. }\end{array}$ & $\begin{array}{l}\text { - Increment of T lymphocytes and macrophages, } \\
\text { depletion of B lymphocytes compared to } \\
\text { uninfected control. } \\
\text { - Lower increment of macrophages and } \\
\text { depletion of B lymphocytes compared of } \\
\text { AF2240 infection. }\end{array}$ \\
\hline Oxidative stress & $\begin{array}{l}\text { - Increment of NO and MDA content compared to } \\
\text { uninfected control. } \\
\text { - Higher increment of NO and MDA content } \\
\text { compared to IBSO02 infection. }\end{array}$ & $\begin{array}{l}\text { - Increment of NO and MDA content compared } \\
\text { to uninfected control. } \\
\text { - Lower increment of NO and MDA content } \\
\text { compared to AF2240 infection. }\end{array}$ \\
\hline $\begin{array}{l}\text { Expression of pro-inflammatory and anti- } \\
\text { inflammatory cykotines/chemokine (CXCLi1, } \\
\text { IFNy, IL18 and IL10) }\end{array}$ & $\begin{array}{l}\text { - Increment of pro-inflammatory cytokines/chemokines } \\
\text { (CXCLi2, IFNy, IL 18) compared to uninfected control. } \\
\text { - Anti-inflammatory IL10 was detected in the bursa } \\
\text { at day } 3 \text { and } 4 \text { post infection but not at day } 1 \text { and } \\
\text { uninfected control. } \\
\text { - Higher increment of pro-inflammatory cytokines/ } \\
\text { chemokines (CXCLi2, IFNy, IL18) compared to } \\
\text { IBS002 infection. }\end{array}$ & 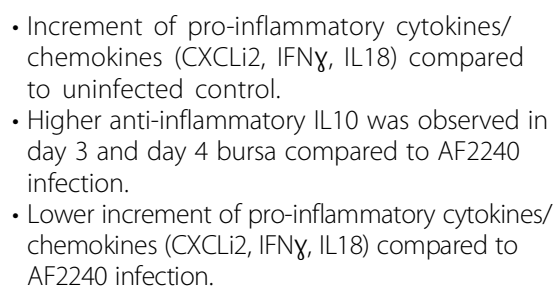 \\
\hline Viral load & $\begin{array}{l}\text { - Viral load was detected in in the bursa at day } 3 \\
\text { and } 4 \text { post infection but not at day } 1 \text { and } \\
\text { uninfected control. } \\
\text { - Lower detected viral load compared to IBSO02 } \\
\text { infection. }\end{array}$ & $\begin{array}{l}\text { - Viral load was detected in in the bursa at day } \\
3 \text { and } 4 \text { post infection but not at day } 1 \text { and } \\
\text { uninfected control. } \\
\text { - Higher detected viral load compared to } \\
\text { AF2240 infection. }\end{array}$ \\
\hline Apoptosis of IgM+ cells & $\begin{array}{l}\text { - Increment of IgM+ apoptotic population over the } \\
\text { infection time. } \\
\text { - Higher increment of IgM+ cell apoptosis } \\
\text { compared to IBSO02 infection. }\end{array}$ & $\begin{array}{l}\text { - Increment of IgM+ apoptotic population over } \\
\text { the infection time. } \\
\text { - Lower increment of IgM+ cell apoptosis } \\
\text { compared to AF2240 infection. }\end{array}$ \\
\hline
\end{tabular}




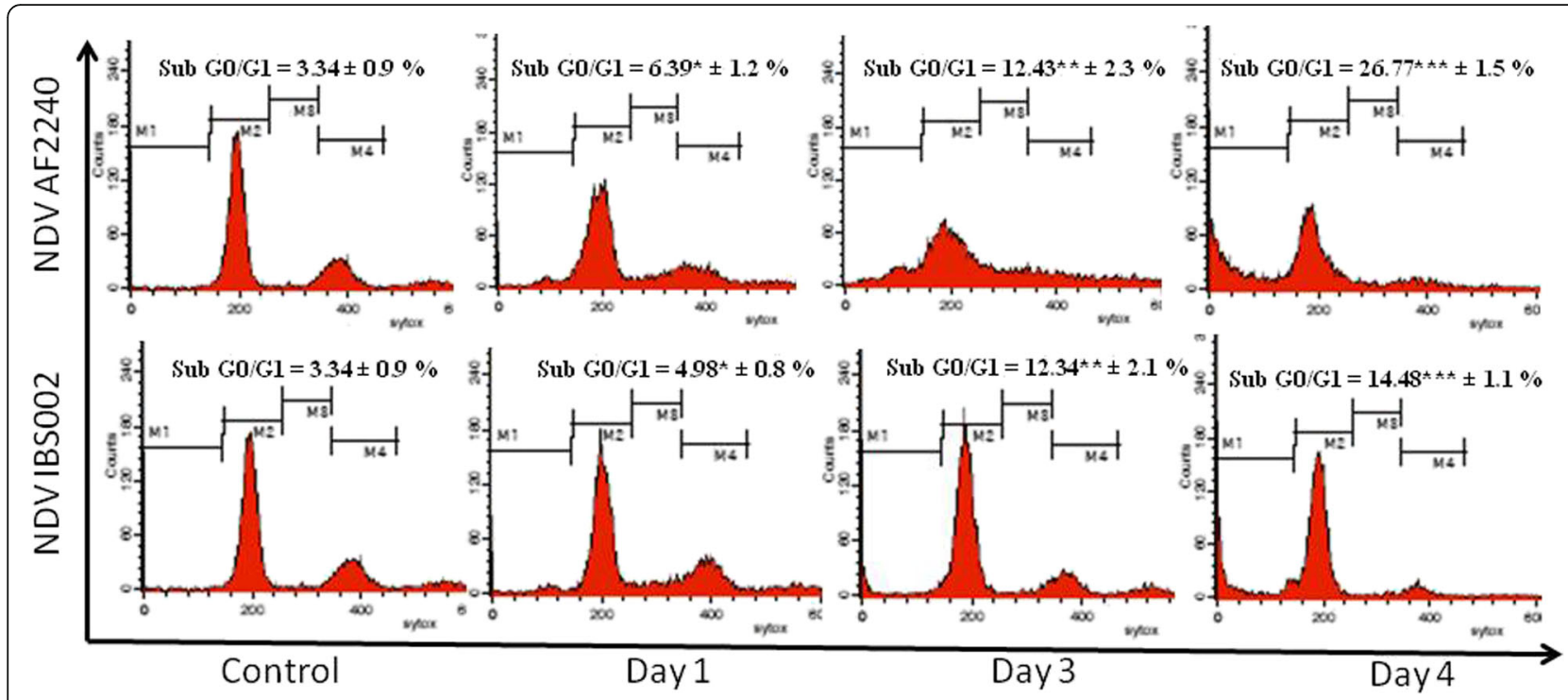

Fig. 5 Pertubations of cell cycle phases of B lymphocytes in the bursa of chicken infected with NDV AF2240 and NDV IBS002 at day 1, 3 and 4 post infections. The sub G0/G1 population differences between the control group and treated group were determined by one-way ANOVA. Groups labelled with different superscript are significantly different $(P \leq 0.05)$

and IBS022 infected chicken bursa. Such a scenario was reported earlier in cases where infections by IBDV and Marek's disease virus caused infiltration of $\mathrm{T}$ cells in the chicken bursa consequently indicating that $\mathrm{T}$ cells, especially CD8+ T cells play a role in combating virus in infected cells in the bursa $[15,17,32]$. It was reported by Rasoli et al. [31] that NDV AF2240 and IBS002 caused decrease of the $\mathrm{T}$ cell population in chicken spleen. Thus, we postulated that migration of $\mathrm{T}$ cells from chicken spleen to the bursa of Fabricius may have taken place during NDV AF2240 and IBS002 infection because in our study, we found that the $\mathrm{T}$ cell number was increased in the chicken bursa during infection. Similar to what was reported earlier, participation of $\mathrm{T}$ cells in virus pathogenicity was observed by the migration of the $T$ cells from the chicken spleen to the bursa during infection by IBDV [33]. The higher accumulation of intrabursal $\mathrm{T}$ cells and macrophages detected in chicken bursa infected by NDV AF2240 than NDV IBS002 was followed by a similar trend of nitric oxide increment in the chicken bursa upon virus infections by both strains of NDV. It was reported that inflammation caused by bacterial and viral infections subsequently caused oxidative damage to both the host cells and the invading microorganisms as result of the action of host defense [34]. A high level of oxidative stress, as indicated by a rise of NO level, was caused by NDV on the organs (Fig. 2). Similarly to what was reported previously, NDV is able to induce the activation of macrophages, which subsequently triggered iNos gene expression and production of $\mathrm{NO}$ at the infected site [35]. The production of $\mathrm{NO}$ at the infected site may also be related to the cytokines being expressed. Rasoli et al. [31] reported that IBS002 NDV strain induced higher level of IL10 which inhibited the production of IFN $\gamma$ upon infection. Not only that, the lower macrophage population, which resulted in a lower NO production was also observed in the case of IBS002 infection. Meanwhile, the product of lipid peroxidation known as MDA can cause damage to the cell at the enzyme, protein or DNA levels subsequently leading to cell death [36, 37]. The content of MDA was measured and the results showed significant activity of lipid peroxidation being detected in chicken bursa infected with NDV AF2240 starting on day 3 post infection while NDV IBS002 caused a significant increase of the MDA level after day 1 post infection. However, the subsequent days showed that the infection by NDV AF2240 caused greater activity of lipid peroxidation in chicken bursa compared to NDV IBS002. As lipid peroxidation can be caused by free radicals such as nitric oxide, we postulate that the increment of MDA level in the chicken bursa upon infection with NDV AF2240 and NDV IBS002 is closely related to the increment of the macrophage population which leads to excess production of nitric oxide. This phenomenon suggests that reactive nitrogen species (RNS) and oxygen species (ROS) caused by excess production of NO and lipid peroxidation, respectively play crucial roles in NDV infection as was reported previously [38].

Other than NO and MDA detections, we also evaluated the viral load and cytokine expression in chicken bursa after infection with the two different strains of NDV. The Taqman based real time PCR results showed that no virus was detected from the chicken bursa cell 
population on the first day of infection as well as in the control chickens. Both NDV AF2240 and IBS002 were detected in the IgM+ cell population starting from day 3 post-infection and the amount of virus increased as the duration of the infection increased. Of the two virus genotypes, NDV AF2240 was reported to have lower amount of virus residing in the cells when compared to infection by NDV IBS002. This result was similar to the recent report by $\mathrm{Hu}$ et al. [23] where higher viral load was able to be detected in the bursa of genotype VII NDV infected chicken compared to infections by genotypes IV and IX. However, $\mathrm{Hu}$ et al. [23] reported that a higher viral load in the bursa of genotype VII infected chicken was always associated with a higher fold of proinflammatory cytokine expression. However, in our case, genotype VIII NDV AF2240 induced higher expressions of the tested proinflammatory cytokines (CXCLi2, IFN- $\gamma$ and IL-18) (Fig. 4) but with lower viral load (Table 2) in the chicken bursa than in the case of NDV IBS002 infection. Chicken CXCLi2, a proinflammatory chemokine, is expressed by and is chemotactic for monocytes [39]. On the other hand, IL-18 is a pro-inflammatory cytokine secreted by various immune and none-immune cells including monocytes, macrophages and lymphocytes that promotes expression of IFN- $\gamma$ by T cells [40], which subsequently activates macrophages to produce $\mathrm{NO}$ $[41,42]$. In our study, higher expressions of CXCLi2, IL-18 and IFN- $\gamma$ were observed in infection by NDV AF2240, especially on day 3 post infection of the infected bursa correlating with the increased number of $\mathrm{CD}^{+} \mathrm{T}$ cells. The drastic increase of IFN $-\gamma$ in NDV AF2240 infected bursa further activated macrophages to produce NO on days 3 and 4 post infection. However, lower expression levels of CXCLi2, IL-18 and IFN$\gamma$ were observed on day 4 post infection particularly in the bursa of NDV AF2240 infected chicken. This may be accounted for by the immune system attempting to restore the drastic elevation of the NO content [43] in the chicken bursa by expressing anti-inflammatory cytokine IL10 [31]. IL10 was not detected in the uninfected and day 1 NDV infected bursa but was detected on day 3 and 4 post NDV infection. Similar to the expression of IL10 in the spleen [31], IL10 expression was higher in the NDV IBS002 infected bursa indicating this cytokine may help to control and lower the level of pro-inflammatory cytokines and NO in the bursa of the NDV IBS002 infected chicken compared to NDV AF2240 infection. Although IL10 expression was associated with a reduction of the proinflammatory cytokines level on day 4, this reaction was not able to relieve the inflammation in the bursa of NDV IBS002 and AF2240 infected chicken.

Infection by both genotypes of NDV was observed to cause decreased viability of $\operatorname{IgM}^{+}$B cells. $\operatorname{IgM}^{+}$B cell was then further enriched from the chicken bursa to further understand the effects of inflammatory stress towards the development of humoral immunity that plays an important role to induce protection via the synthesis of effective antibodies against the virus [44]. As B lymphocytes were observed to be depleted in the bursa upon infection with the virus, the apoptosis assay was carried out. Apoptosis is a controlled cell death mode which is implicated in the pathogenesis of viruses that causes diseases [45]. The hallmarks of apoptosis including cell membrane blebbing, DNA fragmentation and Phosphatidylserine (PS) externalization [46] were evaluated by the $\mathrm{AO} / \mathrm{PI}$ assay and Annexin $\mathrm{V}$ analysis in this study. Our results based on the trypan blue assay showed that NDV AF2240 reduced viability and induced higher apoptotic cell rate in chicken bursa when compared to NDV IBS002. The changes were significantly observed from day 3 post infection. This result was in line with the Annexin V study which also showed that NDV AF2240 induced higher rate of apoptosis in the bursa than NDV IBS002. In the AO/Pi assay, cells showing characteristics of apoptotic cells such as membrane blebbing, chromatin condensation and up taking propidium iodide stain were evaluated. Similar to the Annexin V results, our $\mathrm{AO} / \mathrm{Pi}$ results demonstrated that the time course infection of NDV AF2240 induced greater magnitude of apoptosis in chicken bursa of Fabricius compared to IBS002. From our results, the cell cycle analysis showed that NDV AF2240 resulted in a higher population of sub G0/G1 compared to IBS002, showing that apoptotic events were higher during NDV AF2240 infection as sub G0/G1 indicated DNA fragmentation, which is also one of the apoptotic cells' characteristics. The lower degree of B cell depletion in the bursa of NDV IBS002 infected chicken through apoptosis might contribute to the delayed mortality of IBS002 infected chicken compared to NDV AF2240 [31].

Considering that drastic decline in viability and higher apoptotic rate of B cells were detected in chicken bursa infected with NDV AF2240, which is genotype VIII compared to NDV strain IBS002, which belongs to genotype VII with lower virus residue detected in the organ infected by the former, we deduced that oxidative stress induced by the nitric oxide and lipid peroxidation processes which were noticed in the organ during infection might be the primary cause. Furthermore, NO had been reported to cause events of apoptosis in a variety of cells $[47,48]$, whereas lipid peroxidation could induce apoptosis by depleting ATP production in the cells $[49,50]$. Similarly, the significant infiltration of $\mathrm{CD}^{+} \mathrm{T}$ cells and macrophages, which led to the elevation of IFN- $\gamma$ in NDV AF2240 infected chicken bursa caused higher magnitude of organ damage, failure of antibody production and higher mortality in chicken which suggested that 
the infection of NDV strain AF2240 was far more acute than the infection of NDV strain IBS002 [31]. A summary of the results is listed in Table 4.

\section{Conclusion}

The results of our study demonstrated that the time course infection of NDV AF2240 induced a greater magnitude of apoptosis in chicken bursa $\operatorname{IgM}^{+}$B cells that may further cause impairment of the humoral immunity when compared to IBS002. This might be due to the high level of oxidative stress which led to organ damage in the chicken bursa of Fabricius regardless of the viral load.

\section{Additional files}

Additional file 1: Figure S1. Figure shows (a) Amplification cycles and (b) standard curve for NDV AF2240 NDV ( $E=108.7 \%$; $R^{2}=0.984$; Slope = 3.13) as well as (c) amplification cycles and (b) standard curve for NDV IBS002 $\left(E=100.7 \% ; R^{2}=0.994 ;\right.$ Slope = 3.305). (JPEG $\left.109 \mathrm{~kb}\right)$

\section{Abbreviations}

ANOVA: Analysis of variance; AO/PI: Acridine orange/propidium iodide; BSA: Bovine serum albumin; CD: Cluster of differentiation; cDNA: Complementary DNA; Ct: Cycle threshold; CXCLi2: Chemokine (C-X-C motif) ligand 2; DNA: Deoxyribonucleic acid;

EDTA: Ethylenediaminetetraacetic acid; ELD50: Embryo Lethal Dose 50; ELISA: Enzyme-linked immunosorbent assay; FITC: Fluorescein isothiocyanate; GAPDH: Glyceraldehyde 3-phosphate dehydrogenase; IBDV: Infectious bursal disease virus; ICPI: Intracerebral pathogenicity index; IFN- $\gamma$ : Interferon gamma; IgM: Immunoglobulin M; IL10: Interleukin-10; IL18: Interleukin-18; MDA: Malondialdehyde; MDT: Mean death-time; MTT: 3-(4,5-dimethylthiazol2-yl)-2,5-diphenyl tetrazolium bromide; NDV: Newcastle Disease Virus; NO: Nitric oxide; PBS: Phosphate-buffered saline; PCR: Polymerase chain reaction; PE: Phycoerythrin; PerCp: Peridinin-chlorophyll-protein complex; PS: Phosphatidylserine; RNA: Ribonucleic acid; SPF: Specific-pathogen-free; TBARS: Thiobarbituric acid-reactive substance

\section{Funding}

The study was supported by an Institute of Bioscience, Higher Institution Centre of Excellence (IBS HICOE) grant from the Ministry of Higher Education, Government of Malaysia.

\section{Availability of data and materials}

Data and materials used and/or analyzed during the study are available from the corresponding author upon reasonable request.

\section{Authors' contributions}

KTYW, YSK, OAR, IA, TSG, ANB designed the experiment. KTYW, YSK, TSW carried out the animal trials. KTYW and TSW propagated NDV and performed the qPCR assays. KTYW, YSK performed flow cytometry, and other experiments. KTYW, YSK, OAR, ANB prepared the manuscript. KTYW, YSK, TSW, OAR, IA, TSG, ANB performed data analysis and proof-read the manuscript. All the authors read and approved the final manuscript.

\section{Competing interests}

The authors declare that they have no competing interests.

\section{Consent for publication}

Not applicable.

\section{Ethics approval and consent to participate}

The study was approved by the Institutional Animal Care and Use Committee (IACUC), Universiti Putra Malaysia (UPM) with ethics number UPM/IACUC/AUPR028/2013.

\section{Publisher's Note}

Springer Nature remains neutral with regard to jurisdictional claims in published maps and institutional affiliations.

\section{Author details}

${ }^{1}$ Institute of Bioscience, Universiti Putra Malaysia, 43400 Serdang, Selangor,

Malaysia. ${ }^{2}$ Faculty of Veterinary Medicine, Universiti Putra Malaysia, 43400

Serdang, Selangor, Malaysia. ${ }^{3}$ Faculty of Biotechnology and Biomolecular

Sciences, Universiti Putra Malaysia, 43400 Serdang, Selangor, Malaysia.

Received: 5 January 2016 Accepted: 23 May 2017

Published online: 31 May 2017

\section{References}

1. Mayo MA. A summary of taxanomic changes recently approved by ICTV. Arch Virol. 2002;147:1655-6.

2. Alexander D. Newcastle disease and other Paramyxoviridae infections. In: Calnek B, editor. Diseases of poultry. 10th ed. Ames: lowa State University Press; 1997. p. 541-69.

3. Alexander D. Newcastle disease and other paramyxovirus infections. In: Calnek B, Barnes H, Beard C, Reid W, editors. Diseases of poultry. 9th ed. Ames: lowa State University Press; 1991. p. 469-519.

4. MacPherson LW. Some observation on the epizootiology of Newcastle disease. Can J Comp Med. 1956;20:155-68.

5. Masaji M, Imai K, Sanada Y, Sanada N, Yuasa N, Imada T, et al. Phylogenetic analysis of Newcastle disease virus genotypes loslated in Japan. J Clin Microbiol. 2002;40(10):3826-30.

6. Ke MG, Liu JH, Lin YMH, Chen J, Tsai SS, Chang CP. Molecular characterization of Newcastle disease viruses isolated from recent outbreaks in Taiwan. J Virol Methods. 2001;97:1-11.

7. Hugh-Jones M, Allan WH, Dark FA, Harper GJ. The evidence for the airborne spread of Newcastle disease. J Hyg (Lond). 1973;71:325-39.

8. Alexander D. Newcastle disease: methods of spread. In: Alexander D, editor. Newcastle disease. 1st ed. Boston: Springer US; 1988. p. 256-72.

9. Momayez R, Gharahkhani P, Pourbakhsh SA, Toroghi R, Shoushtari AH, Banai M. Isolation and pathogencity identification of avian paramyxovirus serotype 1 (Newcastle disease) virus from a Japanses quail flock in Iran. Arch Razi Inst. 2007;62(1):39-44.

10. Alexander D. Newcastle disease, other avian paramyxoviruses and pneumovirus infections. In: Saif Y, editor. Disease of poultry. 11th ed. Ames: lowa State Press; 2003. p. 63-92.

11. Glick B. Historical perspective: the bursa of Fabricius and its influence on B-cell development, past and present. Vet Immunol Immunopathol. 1991;30:3-12

12. Alitheen NB, McClure JS, Yeap SK, Kristeen-Teo YW, Tan SW, McCullagh P. Establishment of an in vitro system representing the chicken gut-associated lymphoid tissue. PLoS One. 2012;7(11):e49188.

13. Kozuka Y, Nasu T, Murakami T, Yasuda M. Comparative studies on the secondary lymphoid tissue areas in the chicken bursa of Fabricius and calf ileal Peyer's patch. Vet Immunol Immunopathol. 2010;133:190-7.

14. Imre O, Lonneke V. Structure of the avian lymphoid system. In: Schat K, Kaspers B, Kaiser P, editors. Avian Immunology. 2nd ed. London: Academic Press; 2013. p.13-50.

15. Abdul-Careem MF, Hunter BD, Sarson AJ, Parvizi P, Haghighi HR, Read L, et al. Host responses are induced in feathers of chickens infected with Marek's disease virus. Virology. 2008;370:323-32.

16. Khatri M, Palmquist JM, Cha RM, Sharma JM. Infection and activation of bursal macrophages by virulent infectious bursal disease virus. Virus res. 2005;113:44-50.

17. Kim IJ, You SK, Kim H, Yeh HY, Rautenschlein S, Sharma JM. Chracteristics of bursal T lymphocytes induced by infectious bursal disease virus. J Virol. 2000;74(19):8884-92.

18. Rautenschlein S, Yeh HY, Njenga MK, Sharma JM. Role of intrabursal T cells in infectious bursal disease virus (IBDV) infection: T cells promote viral clearance but delay follicular recovery. Arch Virol. 2002;147(2):285-304

19. Brown C, Kind DJ, Seal BS. Pathogenesis of Newcastle disease in chickens experimentally infected with viruses of different virulence. Vet Pathol. 1999:36:125-32.

20. Kommers GD, King DJ, Seal BS, Carmicheal KP, Brown CC. Pathogenesis of six pigeon-origin isolates of Newcastle disease virus for domestic chickens. Vet Pathol. 2002;39:352-62. 
21. Wakamatsu N, King DJ, Kapczynski DR, Seal BS, Brown CC. Experimental pathogenesis for chickens, turkeys, and pigeons of exotic Newcastle disease virus from an outbreak in California during 2002-2003. Vet Pathol. 2006:43:925-33.

22. Rue CA, Susta L, Cornax I, Brown C, Kapczynski DR, Suarez DL, et al. Virulent Newcastle disease virus elicits a strong innate immune response in chickens. J Gen Virol. 2011;92:931-9.

23. Hu Z, Hu J, Hu S, Song Q, Ding P, Zhu J, et al. High levels of virus replication and an intense inflammatory response contribute to the severe pathology in lymphoid tissues caused by Newcastle disease virus genotype VIld. Arch Virol. 2015;160:639-48.

24. Harrison L, Brown C, Afonso C, Zhang J, Susta L. Early occurrence of apoptosis in lymphoid tissues from chickens infected with strains of Newcastle disease virus of varying virulence. J Comp Pathol. 2011;145:327-35.

25. Murulitharan K, Yusoff K, Omar AR, Molouki A. Characterization of Malaysian velogenic NDV strain AF2240-I genomic sequence: a comparative study. Virus Genes. 2013;46:431-40.

26. Lai MC, Ibrahim A. Velogenic viscerotropic Newcastle disease virus. In: Copland JW, editor. Disease in Poultry: A New Food Pellet Vaccine 5th ed. Canberra: ACIAR. 1987; p. 33-34.

27. Lee TC, Yusoff K, Nathan S, Tan WS. Detection of virulent Newcastle disease virus using a phage-capturing dot blot assay. J Virol Methods. 2006;136:224-9.

28. Roohani K, Tan SW, Yeap SK, Ideris A, Bejo MH, Omar AR. Characterisation of genotype VII Newcastle disease virus (NDV) isolated from NDV vaccinated chickens, and the efficacy of la Sota and recombinant genotype VII vaccines against challenge with velogenic NDV. J vet Sci. 2015;16(4):447-57.

29. Mosmann T. Rapid colorimetric assay for cellular growth and survival: application to proliferation and cytotoxicity assays. J Immunol Methods. 1983;65(1-2):55-63.

30. Luca GG, Francis VC. Noncytolytic control of viral infections by the innate and adaptive immune response. Annu rev Immunol. 2001;19:65-91.

31. Rasoli M, Yeap SK, Tan SW, Moeini H, Aini I, Hair-Bejo M, et al. Alteration in lymphocytes responses, cytokine and chemokine profiles in chickens infected with genotype VII and VIII velogenic Newcastle disease virus. Comp Immunol Microbiol Infect Dis. 2014;37(1):11-21.

32. Rauf $A$, Khatri M, Murgia MV, Saif YM. Expression of perforin-granzyme pathway genes in the bursa of infectious bursal disease virus-infected chickens. Dev Comp Immunol. 2011;35:620-7.

33. Yu X, Rui L, Shao Q, Liu H, Lu Y, Zhang Y, et al. Changes of CD4+CD25+ cells ratio in immune organs from chickens challenged with infectious bursal disease virus strains with varying virulences. Viruses. 2015;7(3): 1357-72.

34. Akaike T. Role of free radicals in viral pathogenesis and mutation. Rev med Virol. 2001;11:87-101.

35. Victor U, Vladimir AS, Volker L, Volker S. Induction of NO synthesis in macrophages by Newcastle disease virus is associated with activation of nuclear factor- KB. Int Immunol. 1996:8(4):491-8.

36. Das U. Selective enhancement of free radicals in tumour cells as a strategy to kill tumour cells both in vitro and in vivo. In: Reddy C, Hamilton G, Madyastha K, editors. Biological oxidation systems. 1st ed. San Diego: Academic Press; 1990. p. 607-24.

37. Kumar SG, Das UN. Free radical dependent suppression of growth of mouse myelomia cells by alpha-linolenic and eicosapentaenoic acid in vitro. Cancer Lett. 1995;92:27-38.

38. Kadiam C, Ventaka S, Rajendra W, Lokanatha V. Newcastle disease virus (NDV) modulates pro/antioxidant status in different brain regions of chicken. Free Radicals Antiox. 2013;3:81-6.

39. Poh TY, Pease J, Young JR, Bumstead N, Kaiser P. Re-evaluation of chicken CXCR1 determines the true gene structure. J Biol Chem. 2008;283:16408-15.

40. Gobel TW, Schneider K, Schaerer B, Mejri I, Puehler F, Weigend S, et al. IL-18 stimulates the proliferation and IFN- $\gamma$ release of $C D 4^{+} T$ cells in the chicken: conservation of a Th1-like system in a nonmammalian species. J Immunol. 2003;171:1809-15.

41. Qureshi MA, Marsh JA, Dietert RR, Sung YJ, Nicolas-Bolnet C, Petitte JN. Profiles of chicken macrophage effector functions. Poult Sci. 1994;73(7):1027-34.

42. Weining KC, Schultz U, Munster U, Kasper B, Staeheli P. Biological properties of recombinant chicken interferon-gamma. Eur J Immunol. 1996;26:2440-7.

43. Akaike $\mathrm{T}$, Maeda $\mathrm{H}$. Nitric oxide and virus infection. Immunology. 2000;101(3):300-8.

44. Rauw F, Gardin Y, Palya V, van Borm S, Gonze M, Lemaire S, et al. Humoral, cell-mediated and mucosal immunity induced by oculo-nasal vaccination of one-day-old SPF and conventional layer chicks with two different love Newcastle disease vaccines. Vaccine. 2009;27:3631-42.

45. Roulston A, Marcellus RC, Branton PE. Viruses and apoptosis. Annu rev Microbiol. 1999:53:577-628.

46. Kerr JFR, Wyllie AH, Currie AR. Apoptosis: a basic biological phenomenon with wide ranging implications in tissue kinetics. Br J Cancer. 1972;26:239-57.

47. Albina JE, Cui S, Mateo R, Reichner JS. Nitric oxide-mediated apoptosis in murine peritoneal macrophages. J Immunol. 1993;150:5080-5.

48. Cui S, Reichner JS, Mateo RB, Albina JE. Activated murine macrophages induce apoptosis in tumor cells through nitric oxide-dependent or independent mechanisms. Cancer res. 1994;54:2462-7.

49. Fernandes $G$, Chandra SB, Luan X, Troyer DA. Modulation of antioxidant enzymes and programmed cell death by n-3 fatty acids. Lipids. 1996;31:591-6.

50. Southgate J, Pitt E, Trejdoesiewicz LK. The effects of dietary fatty acids on the proliferation of normal human arothelial cells in vitro. $\mathrm{Br} J$ Cancer. 1996;74:728-34

\section{Submit your next manuscript to BioMed Central and we will help you at every step:}

- We accept pre-submission inquiries

- Our selector tool helps you to find the most relevant journal

- We provide round the clock customer support

- Convenient online submission

- Thorough peer review

- Inclusion in PubMed and all major indexing services

- Maximum visibility for your research

Submit your manuscript at www.biomedcentral.com/submit

) Biomed Central 